\title{
COULD EDRIOASTEROIDS MOVE?
}

SUMRALL*, Colin D. and SPRINKLE, James, Department of Geological Sciences, University of Texas, Austin Texas 78713-7909, USA.

Edrioasteroids are an extinct group of primitive echinoderms whose geologic range is Early Cambrian to Late Pennsylvanian. Several authors have argued whether edrioasteroids could freely move about on the sea floor or were firmly attached to a hard substrate throughout post-larval life. Arguments that edrioasteroids were mobile are based primarily on orientation of individuals within a population and positioning of individuals on a host shell. We disagree with these arguments based on overwhelming evidence that edrioasteroids could not move and remained firmly attached throughout post-larval life.

Edrioasteroids have specialized attachment structures that are almost always found on hard substrates such as hardgrounds, fossil shells or fragments, and conglomerate pebbles. There are two types of edrioasteroid attachment structures, an aboral disk and a peripheral rim. Edrioasteroids with an aboral disk are typically found attached to hard substrates. Although some individuals have been found loose in muddy sediment, many of these individuals show signs of being torn loose from their attachment surface based on their inverted orientation, disrupted attachment structures, and shingling by currents. Edrioasteroids with a peripheral rim are almost never found free in the sediment, and the few known examples of this are either small juveniles indicating that soft substrates probably could not support adult edrioasteroids or else thickrimmed adults apparently attached to soft algae.

In uncrowded conditions, edrioasteroids are circular in outline, but they become polygonal and abutting under crowded conditions. Other encrusters such as tube worms also affect their peripheral outline. Edrioasteroids occur in crowded clumps even though nearby skeletal grains are uncolonized. In these individuals, peripheral rims and oral surfaces are severely distorted which would make living conditions and continued growth difficult. Also, some individuals attach to objects much smaller than their eventual thecal diameter. In such conditions, the edrioasteroid gradually engulfs the object it is attached to, severely distorting the animal, with the peripheral rim migrating toward the bottom of the attachment object. Under either of these conditions, individuals would almost certainly have moved to nearby open spots or to larger, uncolonized clasts if they could.

In crowded conditions, individuals of the same species do not overgrow one another, but individuals of one species will overgrow living individuals of another species competing for the same attachment space. Two localities preserve large edrioasteroids partially overgrowing smaller articulated individuals of a different species. Because they are fully articulated, overgrown individuals must have been alive during the overgrowth, but were not able to move out of the way.

Disrupted edrioasteroids are often found with the oral surface completely disarticulated or missing, but with a completely articulated peripheral rim. Apparently, the peripheral rim was firmly attached to the substrate and more strongly constructed than the oral surface and therefore better able to withstand wave activity, death and decay, and subsequent disarticulation than the oral surface. This firm attachment to hard substrates also suggests lack of movement.

The edrioasteroid attachment grows from the periphery. New ossicles are added to distal plate circlets of the attachment while plates in more proximal circlets enlarge. Clearly some degree of movement is required for this type of growth but not active locomotion. Large edrioasteroids growing along the margin of a large skeletal fragment show an underdevelopment of the peripheral rim along this edge even though the rest of the animal is round and symmetrical.

Some authors have used living psolid holothurians as a good analog for extinct edrioasteroids with a peripheral rim. Psolids will move using tube feet under the theca in the ventrally positioned A, B, and E rays under extreme disturbance, but only at the rate of a few millimeters per day. Edrioasteroids have all the ambulacra dorsally oriented away from the substrate and therefore have no similar mechanism for locomotion. We suggest balanimorph barnacles as a better analog for the vast majority of edrioasteroids. They firmly attach to a hard substrate, become polygonal in crowded conditions, have feeding structures facing upward, grow from the periphery of the attachment surface, and do not move as adults. 